\title{
Removal of Acid Dye from Aqueous Solutions with Adsorption onto Modified Wheat Bran - Modeling with Artificial Neural Networks
}

\author{
Leili Mohammadi ${ }^{1}$, Marzieh Baniasadi ${ }^{2}$, Abbas Rahdar ${ }^{3, *(\mathbb{D})}$, George Z. Kyzas ${ }^{4, *(\mathbb{D})}$ \\ 1 Infectious Diseases and Tropical Medicine Research Center, Resistant Tuberculosis Institute, Zahedan University of \\ Medical Sciences; lailimohamadi@gmail.com (L.M.); \\ 2 Health school, Zahedan University of Medical Sciences, Iran; Marzieh.bns76@gmail.com (M.B.A.); \\ 3 Department of Physics, University of Zabol, Zabol 98613-35856, Iran; a.rahdar@uoz.ac.ir (A.R.); \\ 4 Department of Chemistry, International Hellenic University, Kavala, GR-654 04, Greece; kyzas@ chem.ihu.gr (G.Z.K.); \\ * Correspondence: kyzas@chem.ihu.gr (G.Z.K.), a.rahdar@uoz.ac.ir (A.R);
}

Scopus Author ID 17345938100 (G.Z.K.)

Received: 24.01.2021; Revised: 20.02.2021; Accepted: 24.02.2021; Published: 2.03.2021

\begin{abstract}
In this study, the removal of 2-Naphthol Orange dye known as Acid Orange 7 (AO7) from aqueous solutions was studied using a modified adsorbent of wheat bran. The efficiency of neural networks in predicting biological uptake was also investigated. The effect of initial concentration, adsorbent dose, $\mathrm{pH}$, velocity, and mixing time in a discontinuous reactor on the adsorption of 2-naphthol orange dye was investigated. Part of the laboratory results was amplified by a feed-forward-backpropagation neural network, and another part was simulated to measure the accuracy of the model. The transmission function and a number of hidden layer neurons were optimized. Optimum conditions were obtained at an initial concentration of $250 \mathrm{mg} / \mathrm{L}$, an adsorbent dose of $0.07 \mathrm{~g} / \mathrm{L}$, a pH of 3, a mixing rate of $200 \mathrm{rpm}$, and a mixing time of $120 \mathrm{~min}$, with a maximum removal rate of $99 \%$ and a maximum adsorption capacity of $92.64 \mathrm{mg} / \mathrm{g}$. The dye adsorption kinetics and adsorption equilibrium (isotherm) were found to follow the quasi-second order and Freundlich model, respectively. In the designed neural network, the best transfer function in the sigmoid tangent function's hidden and output layers and the number of optimal neurons was determined to be 13. The model output had a proper correlation with the target vector $(\mathrm{R}=0.986)$. Also, the simulations performed by the neural network model were in good agreement with the experimental results.
\end{abstract}

Keywords: 2-Naphthol Orange dye; activated carbon; wheat bran; modeling; artificial neural networks.

(C) 2021 by the authors. This article is an open-access article distributed under the terms and conditions of the Creative Commons Attribution (CC BY) license (https://creativecommons.org/licenses/by/4.0/).

\section{Introduction}

Dyes are widely used in textiles, leather, paper, plastics, and other industries [1-3]. They are materials with a complex structure entering the environment through various processes such as dyeing and finishing in the textile industry [4]. Thus, the consumed loads of water are the main producer of industrial wastewater [5]. Excessive dye in wastewater can reduce water transparency and photosynthesis. Therefore, colored effluents must be filtered before discharge to reduce the environmental threat $[3,6]$. Typically, dyes are reactive, dispersed, acidic, and direct [7]. Several methods, such as bioremediation, coagulation-flocculation, ozone treatment, electrochemical coagulation, chemical oxidation, membrane filtration, ion exchange, photocatalytic decomposition, and surface absorption, have been developed to remove these 
compounds from colored effluents [8-11]. Although bioremediation is less expensive than other methods, it is not used in decolorization since dyes are toxic, reducing this method's removal efficiency significantly [12].

Most studies on dye removal are based on advanced oxidation processes; however, despite the high rate of dye removal capability, such processes form by-products that are considered one of their disadvantages. The absorption process is simple, effective, and easy to be used $[5,6]$.

Among these methods, biological absorption using agricultural inputs has attracted the close attention of researchers. Some of its benefits are its high efficiency, cheapness, availability, and controllability [13]. Sugarcane pulp, rice paddy, sawdust, coconut husk, and almond shell are among the wastes used for biological absorption [14].

Since this process is low cost and environmentally friendly with excellent absorption efficiency, it is being increased as an efficient alternative to conventional methods of removing pollutants from the aquatic environment [15]. Thus, in recent years, agricultural by-products and wastes, such as tree bark, sawdust, pistachios, rice and wheat bran, corn wastes, have been increasingly used due to the presence of cellulosic compounds, carbon, and silica in their chemical structure to absorb heavy metals of water and wastewater, as well as their high efficiency and economic benefits [16].

These biological wastes are very abundant and available, not being used for any particular process. Adsorption studies using plant residues began mainly in the 1970s. Larsen and Schroop, who used straw activated carbon to remove cadmium, were pioneers in this field [17]. In this period, studies were performed mainly using raw plant residues and charcoal. In the late 1990s, adsorption studies using plant residues were performed; thus, chemical activation or modification was used instead of physical activation (activated carbon). In this method, while increasing the absorption capacity and reducing the equilibrium time, the activation costs are much lower than the physical activation method.

In this regard, the research of Ajmel et al. can be referred to according to which the adsorption efficiency by phosphate-modified rice bran husk with a concentration of $1 \mathrm{M}$ was much higher than raw bran husk [18]. Sisar et al. studied the use of modified rice bran husk as a natural adsorbent of heavy metals for cadmium and lead; their results showed bran husk to sodium hydroxide modified with solution $0.75 \mathrm{M}$ to have a higher adsorption capacity for both metal cations compared to raw bran [19]. Kumar and Manas studied cadmium absorption by rice bran modified with chlorohydrin, sodium hydroxide, and sodium bicarbonate; they suggested sodium bicarbonate as the preferred corrective solution due to its low preparation cost [20].

Biological adsorption is highly complex due to the involvement of many parameters with non-linear relationships in this process. Modeling the biological adsorption process in the Batch system with conventional mathematical models is very difficult [21]. Due to the salient, firm, and reliable characteristics of artificial neural networks in achieving/establishing nonlinear relationships between input and output data, these models have been widely used in environmental engineering in the last decade. These models and their ability to predict the biological adsorption process are being studied by many researchers [22]. The present research is in line with the mentioned studies. ANN programs have been used for a variety of processes, including modeling and optimizing sludge bulking in a wastewater treatment plant (WWTP) using ANN [23], Predicting the water quality using genetic algorithm [24], Modeling the NOx propagation rate using ANN [25], Diffusion modeling of solid waste incineration using neural 
network [26], Biological adsorption modeling of Acid Black and Congo Red of aqueous solutions using ANN [27].

Therefore, due to the necessity of applying economical, efficient, and eco-friendly methods, this study first aimed at chemical modifying wheat straw by sodium bicarbonate and evaluating it in eliminating 2-naphthol orange dye. Secondly, it investigated adsorption kinetics and adsorption isotherm models as key factors in designing adsorption systems to determine the adsorbent capacity and optimize its consumption. The effects of different parameters, such as absorption dose, initial concentration, $\mathrm{pH}$, mixing speed, and mixing time, were studied in a discontinuous reactor. Experimental results were modeled by a feed-forward-back-propagation neural network of three-layer. The type of transfer function and the number of neurons in the hidden layers and the output were optimized; finally, the model output was compared with the laboratory results.

\section{Materials and Methods}

Wheat straw was prepared from local plants. To obtain an unmodified adsorbent, wheat straw was first crushed by a mill, then separated using sieves of number 30 and 40 (average size of 500 microns) with the desired diameter amplitude and washed well with plenty of water. After rinsing with deionized water, it was dried in an oven at $90{ }^{\circ} \mathrm{C}$ for $3 \mathrm{~h}$ and kept under the name Straw Wheat Raw (RWS) for later use. Next, to prepare the modified adsorbent, $100 \mathrm{~g}$ of RWS was added to 2 liters of sodium bicarbonate solution $(0.4,0.7$, and 1 molar) and was mixed for $4 \mathrm{~h}$. After completing the activation for removing the excess sodium bicarbonate from the modified straw, the straw was rinsed several times with distilled water without ions. The adsorbents were dried at $90{ }^{\circ} \mathrm{C}$ for $5 \mathrm{~h}$ and stored under the general name Sodium Bicarbonate Modified Wheat Straw (SBMWS), including three subsets of SBMWS1, SBMWS2, and SBMWS3, in a sealed glass container.

An acid dye, namely 2-naphthol orange dye (purchased from Sigma-Aldrich, USA) was used to prepare the samples. A dye of acidic type was prepared with the formula $\mathrm{C}_{16} \mathrm{H}_{11} \mathrm{~N}_{2} \mathrm{NaO}_{4} \mathrm{~S}$, a molecular weight of $350.33 \mathrm{~g} / \mathrm{mol}$, and a maximum wavelength of $484 \mathrm{~nm}$ [28]. To prepare solutions with specific concentrations, $100 \mathrm{mg}$ solution per liter of color was used. According to the initial experiments and similar studies, various variables, including contact time, $\mathrm{pH}$, initial color concentration, adsorbent dose, and mixing intensity, were studied the color removal. Sodium hydroxide and $0.1 \mathrm{~N} \mathrm{HCl}$ were used to adjust the $\mathrm{pH}$ of the samples.

\subsection{Instrumentation/glassware.}

In this research, glass equipment, including pipette, balloon, graduated cylinder, metal sieve, sampling containers, and Whatman brand membrane filter, besides several devices, such as a shaker (Rotator 430R), a pH meter (Ion Analyzer 3045), a magnetic stirrer (3000MR), a digital scale (Sartorius) with an accuracy of $2.5 \mathrm{~g}$, and a spectrophotometer (UV-RAYLEIGH), were used.

\subsection{Experimental design.}

The design of an experiment has an effective role in improving process performance. Among the different methods for designing the experiment, the full factorial design method was used. In this method, the number of experiments is calculated as the total number of permutations obtained by calculating different levels of studied factors [29]. Given the factors 
and their levels (see Table 1) and the replication of the experiment, a total of 296 tests were performed to optimize the adsorption parameters in this study.

Table 1. Parameters and levels intended for experiments.

\begin{tabular}{|c|c|c|c|c|c|}
\hline & \multicolumn{5}{|c|}{ Variables and parameters } \\
\hline & $\begin{array}{c}\text { Dye initial } \\
\text { concentration }(\mathrm{mg} / \mathrm{L})\end{array}$ & pH & $\begin{array}{c}\text { Absorbent dose } \\
(\mathrm{g} / \mathrm{L})\end{array}$ & $\begin{array}{l}\text { Mixing speed } \\
(\mathbf{r p m})\end{array}$ & $\begin{array}{l}\text { Process time } \\
(\text { min) }\end{array}$ \\
\hline $\begin{array}{ll}\text { Optimization } & \text { of } \\
\text { adsorption parameters }\end{array}$ & $50,100,150,200,250$ & $\begin{array}{l}3,5,7,9, \\
11\end{array}$ & $\begin{array}{l}0.01,0.03,0.05, \\
0.07,0.09\end{array}$ & 200 & 120 \\
\hline $\begin{array}{ll}\text { Mixing } \\
\text { optimization }\end{array}$ & $50,100,150,200,250$ & 5 & 0.07 & $\begin{array}{lll}15, & 50, & 100, \\
200 & & \\
\end{array}$ & 120 \\
\hline $\begin{array}{l}\text { Investigation } \\
\text { adsorption kinetics }\end{array}$ & $50,100,150,200,250$ & 5 & 0.07 & 200 & $\begin{array}{l}5,15,30,60, \\
120\end{array}$ \\
\hline $\begin{array}{ll}\text { Investigation } & \text { of } \\
\text { adsorption isotherms } & \end{array}$ & $50,100,150,200,250$ & 5 & $\begin{array}{l}0.01,0.03,0.05, \\
0.07,0.09\end{array}$ & 200 & 120 \\
\hline
\end{tabular}

Discontinuous biological adsorption tests: First, the color solution with initial concentration was made using dilution; then, the solution's $\mathrm{pH}$ was adjusted using hydrochloric acid and sodium hydroxide. Later, $25 \mathrm{~mL}$ samples were prepared from the color solution, at the desired concentrations, were then exposed to the adsorbent of modified wheat bran in certain masses at laboratory temperature of $2 \pm 25$, and were placed on the shaker for $2 \mathrm{~h}$ (or consecutive times in the kinetics experiment and mixing speed optimization). After mixing, the samples were passed through the filter, and the color concentration in the resulting samples was calculated using the colorimetric method according to the standard procedure of 3500 [28] by a spectrophotometer at $484 \mathrm{~nm}$.

Due to the increased number of experiments in the full factorial method, the mixing speed was removed from the factors, and the mixing speed optimization was carried out separately using a series of experiments according to Table 1 . After reaching an optimal mixing rate, all factorial experiments were performed at this optimum velocity [29].

In order to study changes of color absorption over time (adsorption kinetics), experiments were performed, with conditions given in Table 1, on samples of $25 \mathrm{~mL}$ of the color solution with the desired concentration at laboratory temperature. Also, adsorption isotherm experiments were performed according to the considered levels, as given in Table 1, to determine the relationship between the amount of adsorbed dye per adsorbent mass unit and the dye's equilibrium concentration in the solution phase.

$$
\text { Removal }(\%)=\left(\frac{C_{0}-C_{e}}{C_{0}}\right) \cdot 100 \%
$$

The elimination percentage of 2-naphthol orange, introduced as an output parameter to the ANN model, was determined by Eq. 1, where $\mathrm{C}_{0}$ and $\mathrm{Ce}$ are the solution's initial and final concentrations.

Statistical results of adsorption experiments: Experiments were carried out under the mentioned conditions, and the normality of the data was examined by the KolmogorovSmirnov test in the SPSS software.

The average elimination percentage in the whole tests, standard deviation, and P-value were $75.76 \%, 12.28 \%$, and $0.016 \%$, respectively. The result of the Kolmogorov-Smirnov test indicated that the data followed the normal distribution.

Modeling the absorption of AO7 dye by a neural network was done: Artificial neural networks are computer models based on simple models of biological activities of the human brain, such as learning, thinking, reasoning, and problem-solving. 
The neural network models are composed of neural cells and weights; these models are based on the basic principle that a continuous system of simple processor elements can learn complex relationships between the independent and interdependent variables [30]. The development of a neural network model is not simple and involves several steps, including selecting data production strategies, producing data, processing data, selecting neural network structure, selecting network training algorithm, training network, testing a trained neural network, and using the trained neural network for validation and simulation [31].

Neural networks have a continuous structure consisting of the input layer, the output layer, and intermediate layers called hidden layers. Each layer consists of simple processor elements termed a neuron. Neurons are connected to the layers via the weights of the tuned signals. The input layer receives these signals from external sources. This layer is weighted separately for each entry, and then this information is sent to the hidden layers for processing [32].

The hidden layers perform preprocessing steps and transfer results to other hidden layers and the output layer using transfer functions [30]. In the feed-forward neural network, data are transmitted only in one direction, forward, and there are no loops or cycles, as mentioned, in these networks from the input layer to the hidden and from the hidden to the output.

In this study, the MATLAB software was used to predict the removal rate. The results of 80 experimental tests were used to develop the neural network model (ANN), and the results of 20 experiments were considered for simulation at the final step. The results of the experiments conducted for optimization of contact time and mixing speed did not enter the model, and only the experimental results from the optimization of the adsorption parameters and the adsorption isotherm as input and output were entered.

Given that there is no specific global strategy for choosing neural network architecture and algorithm for various issues [15], researchers are working on different neural networks to achieve the most appropriate model in the issues. In this study, to determine the most appropriate transfer functions in hidden layers and the output layer in predicting adsorption, four backpropagation neural network (BPNN) models were developed with three layers of input, hidden, and output with different transfer functions in them. In these four models, purelin-purelin, purelin-tansig, tansig-purelin, and tansig-tansig transfer functions were used, respectively, in the hidden layer and the output layer. The data obtained in the laboratory were introduced as input matrix and output matrix. $70 \%, 15 \%$, and $15 \%$ of the data required for network design were allocated for training, validation, and testing, respectively. The data selection for the mentioned cases is made randomly by the software.

In the neural network architecture, the number of neurons in the input layer was 5, equal to the model's number of input variables. The number of neurons in the hidden layer initially was considered to be 10 .

After determining the best network among the four, the number of hidden layer neurons was optimized. The number of neurons in the output layer depends on the number of network output parameters. In this study, the model output was the elimination percentage of 2-naphthol orange. Therefore, the number of neurons in the output layer was one. The neural network function was evaluated by MSE and correlation coefficient (R), whose equations are in the following.

$$
\text { MSE }=\frac{\sum_{i=1}^{n}\left(y_{o b s, i}-y_{\text {model }, i}\right)^{2}}{n}
$$




$$
\mathrm{R}=\frac{\sum_{\mathrm{i}=1}^{\mathrm{n}}\left(\mathrm{y}_{\mathrm{obs}, \mathrm{i}}-\mathrm{y}_{\text {obs,mean }}\right)\left(\mathrm{y}_{\text {model }, \mathrm{i}}-\mathrm{y}_{\text {model,mean }}\right)}{\sqrt{\sum_{\mathrm{i}=1}^{\mathrm{n}}\left(\mathrm{y}_{\text {obs }, \mathrm{i}}-\mathrm{y}_{\text {obs,mean }}\right)^{2}\left(\mathrm{y}_{\text {model }, \mathrm{i}}-\mathrm{y}_{\text {model,mean }}\right)^{2}}}
$$

In the above equations, $\mathrm{n}$ represents the number of data, and (yobs,i) and ( $\mathrm{y}$ model,i) are the predicted output value by the model and the measured output value, respectively; also, (yobs,mean) and (y model,mean) are the average of output values measured in the laboratory and the average of the value predicted by the model, respectively [30].

Levenberg-Marquardt backpropagation (LMBP) algorithm is used to train the network. In Figure 1, the algorithm steps are simplified. Generally, in function estimation problems with network parameters less than 100, the LMBP algorithm has a high performance and speed, and its top accuracy is quite prominent since, in many cases, the algorithm has the least fault [33].

During the training, the output predicted by the model is compared with the expected output, and the mean-square error is calculated. Suppose the MSE is higher than the estimated value. In that case, the error rate is backpropagated from the output to the input. The weights are modified until the error reaches the allowed limit, or the number of effort and error is equal to the maximum number of effort and error specified for the model. The modification of the weights is done at each time with the following equation:

$$
\Delta \mathrm{W}(t)=-\eta \cdot \mathrm{MSE}+\alpha \cdot \Delta \mathrm{W}(t-1) \Delta \mathrm{W}(\mathrm{t})=-\eta \cdot \mathrm{MSE}+\alpha \cdot \Delta \mathrm{W}(\mathrm{t}-1)
$$

Where $\eta$ is equal to the training rate and $\alpha$ is the momentum coefficient, both in the range 0 to 1 .

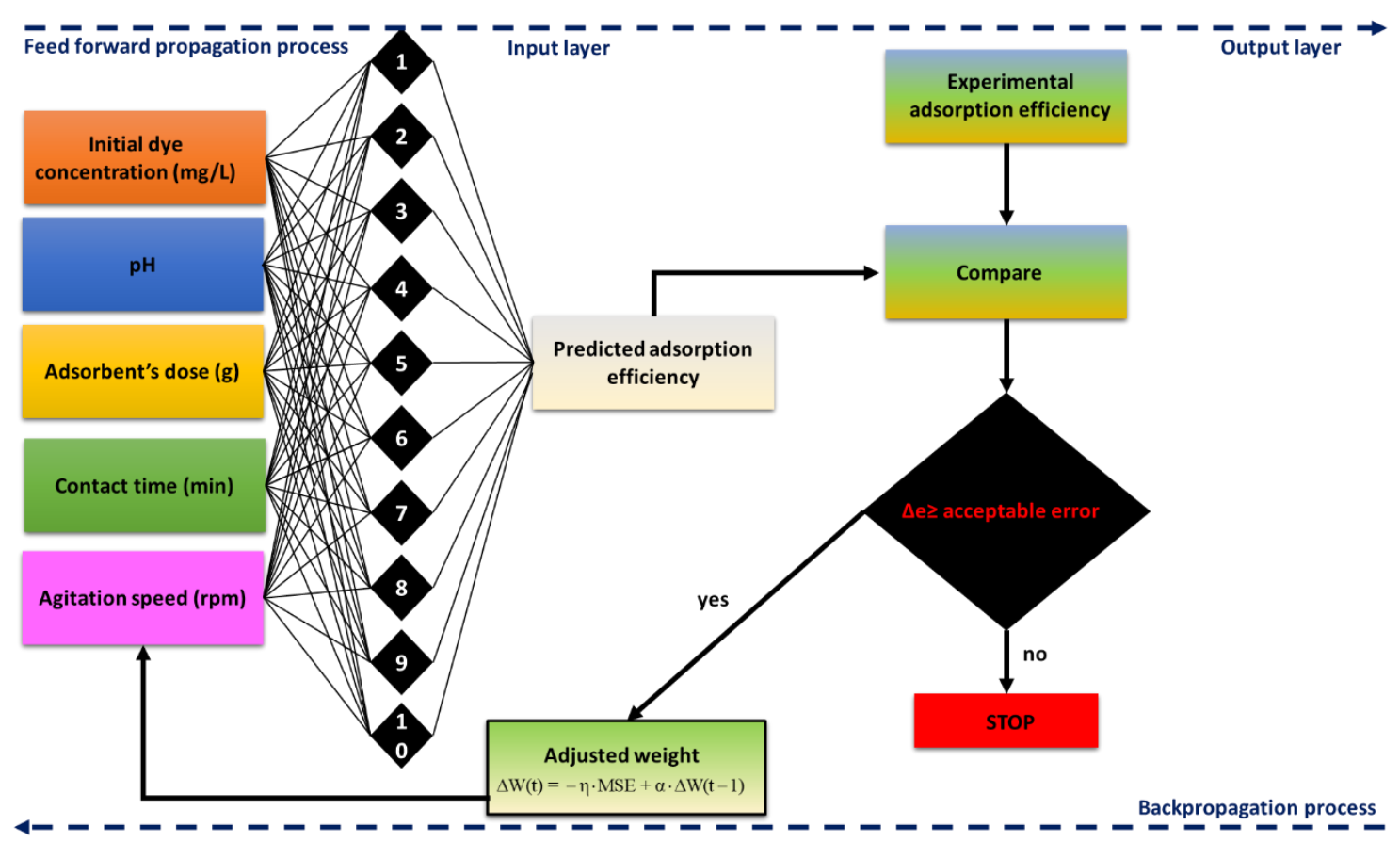

Figure 1. Neural network architecture with a diagram of LMBP algorithm to predict the percentage remove of AO7 from aqueous media by modified wheat bran.

The mean-square error during the training period is monitored. In the training first phase, the error is reduced until the network reaches the minimum error, and then by giving more data, the error increases. Next, the network training is stopped, and the weights are brought back in the minimum error [34]. In Fig. 1, the neural network architecture and the 
LMBP algorithm diagram are shown for predicting the elimination percentage of 2-naphthol orange dye.

\section{Results and Discussion}

Kinetics and isotherms AO7 adsorption: The diagram of 2-naphthol orange dye adsorption kinetics at an initial concentration of 50,100,150,200, and $250 \mathrm{mg} / \mathrm{L}$ is shown in Figure 2. In the studies, quasi-first-and second-order rate constants were used to describe the adsorption kinetics on adsorbents.

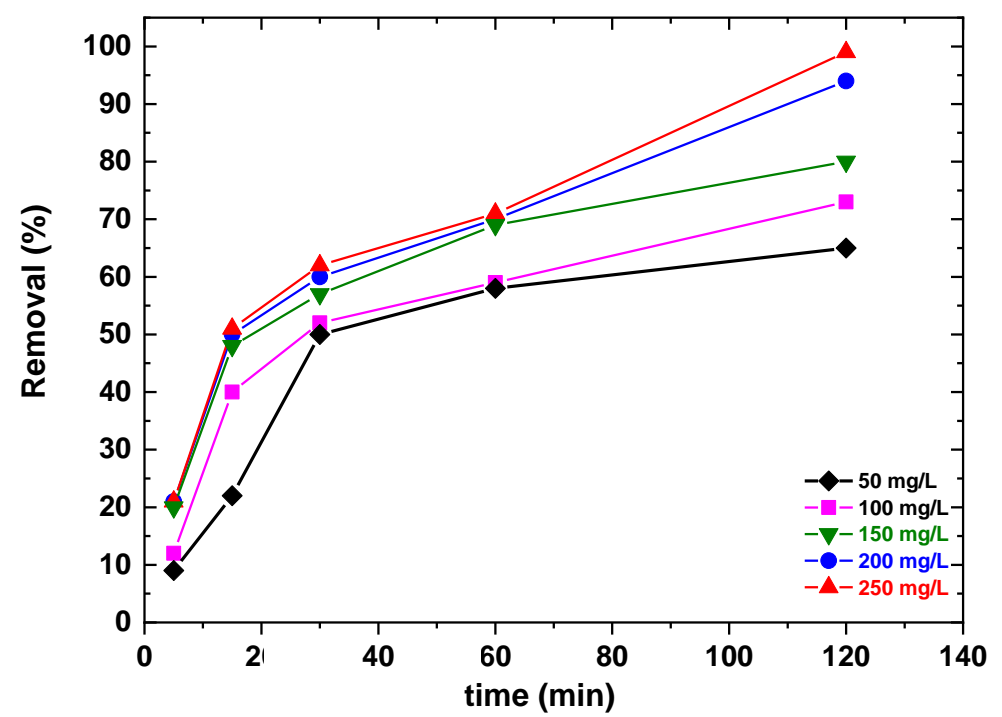

Figure 2. The rate of removal of AO7 by Modified Wheat Bran from Aqueous Solutions over time in different dye concentrations.

Further, Langmuir and Freundlich's models were used to describing adsorption isotherms. The coefficients of the studied isotherms (in Table 2) and Langmuir and Freundlich isotherm diagrams at the initial concentration of $250 \mathrm{mg} / \mathrm{L}$, are illustrated in Figures 3a and 3b.

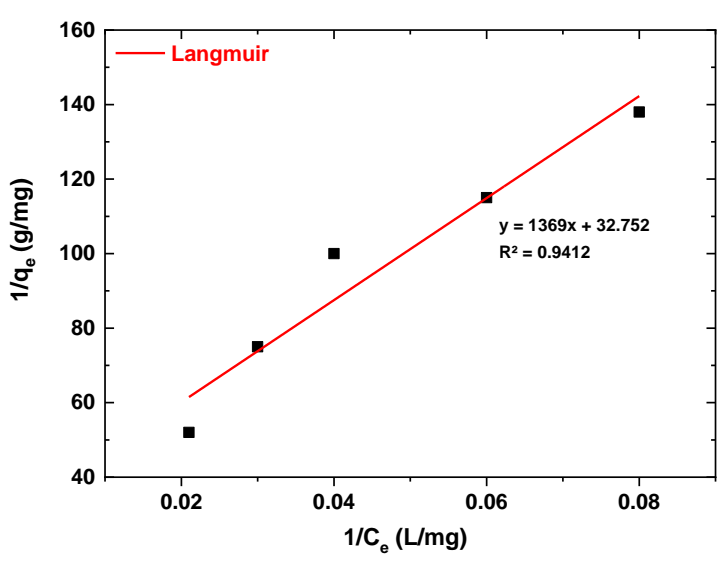

(a)

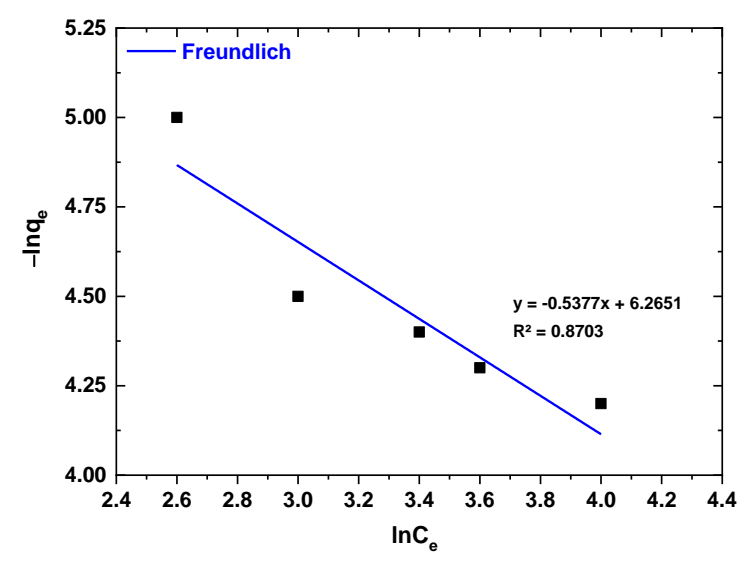

(b)

Figure 3. (a) Langmuir isotherm and (b) Freundlich isotherm of AO7 removal by adsorption onto modified wheat bran $\left(\mathrm{C}_{0}=250 \mathrm{mg} / \mathrm{L}\right)$.

In the figures and the table, qe is the concentration in the solid phase in an equilibrium state in $\mathrm{mg} / \mathrm{g}, \mathrm{C}_{\mathrm{e}}$ is the concentration in the liquid phase in a stable state in $\mathrm{mg} / \mathrm{L}$, a is the Langmuir adsorption equilibrium constant in $\mathrm{L} / \mathrm{mg}$, $\mathrm{b}$ is the ultimate capacity of monolayer adsorption in $\mathrm{mg} / \mathrm{g}$, and also $\mathrm{K}_{\mathrm{f}}$ and $\mathrm{n}$ are the equilibrium constants of Freundlich model. 
Table 2. Equilibrium parameters of Langmuir and Freundlich fitting.

\begin{tabular}{c|c|c|c|c|c|c|c}
\multicolumn{4}{c|}{ Langmuir isotherm } \\
\hline $\mathrm{C}_{0}(\mathrm{mg} / \mathrm{L})$ & $\mathrm{K}_{\mathrm{f}}(\mathrm{xxx})$ & $\mathrm{n}$ & $\mathrm{R}^{2}$ & $\mathrm{C}_{0}(\mathrm{mg} / \mathrm{L})$ & $\mathrm{b}(\mathrm{mg} / \mathrm{g})$ & $\mathrm{a}(\mathrm{L} / \mathrm{mg})$ & $\mathrm{R}^{2}$ \\
\hline 250 & 537.7 & 6.26 & 0.87 & 250 & 0.0002 & 0.32 & 0.941
\end{tabular}

Modeling the absorption of AO7: In the first step, four neural networks were modeled using tangent-sigmoid and purelin transfer functions to determine the best transfer function in the hidden and output layers. In Figure 4, the least-squares error and correlation coefficient are shown in the four fabricated models. This figure shows the fourth model has the least-squares error and the maximum correlation coefficient with the tangent-sigmoid transfer function in the hidden layer and the output layer and 10 neurons in the hidden layers.

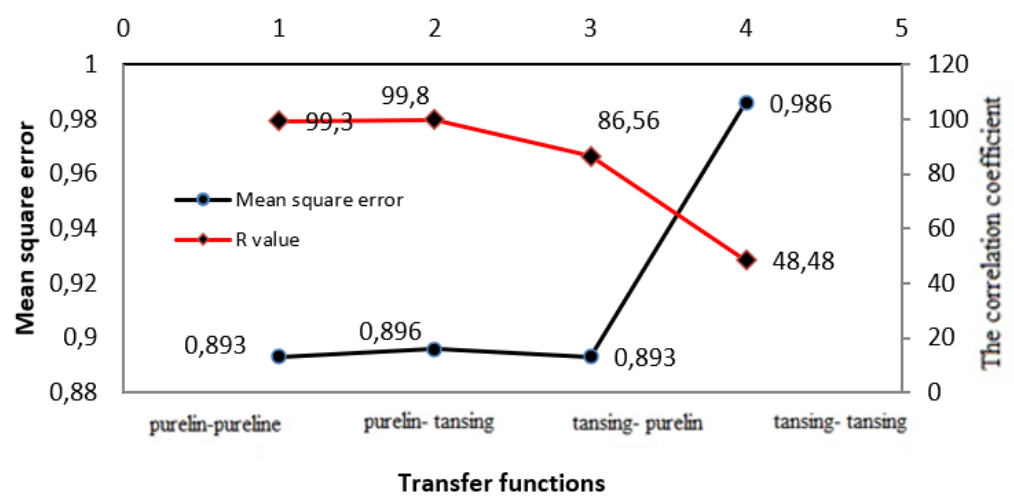

Figure 4. Minimum error values and correlation coefficient in the four models created to determine the best composition of the transfer function.

To determine the optimal number of neurons in the hidden layer, the neural network with the architecture mentioned and only different neurons in the range of 1-100 was developed, and the least-squares error and the correlation coefficient were obtained for each network, as presented in Table 3.

Table 3. Minimum error values and correlation coefficient in neural networks are designed to determine the optimal number of neurons.

\begin{tabular}{c|c|c} 
Number of neurons & Mean square error & Correlation coefficient \\
\hline 1 & 0.893 & 79.3 \\
\hline 2 & 0.896 & 99.8 \\
\hline 3 & 0.893 & 86.56 \\
\hline 4 & 0.986 & 48.48 \\
\hline 5 & 0.892 & 66.5 \\
\hline 6 & 0.996 & 19.01 \\
\hline 7 & 0.899 & 56.98 \\
\hline 8 & 0.981 & 22.02 \\
\hline 9 & 0.982 & 16.99 \\
\hline 10 & 0.991 & 12.98 \\
\hline 11 & 0.969 & 35.98 \\
\hline 12 & 0.968 & 28.98 \\
\hline 13 & 0.961 & 8.02 \\
\hline 20 & 0.981 & 28.03 \\
\hline 50 & 0.929 & 229.8 \\
\hline 100 & 0.698 & 350.03
\end{tabular}

The neural network model with 13 neurons in the hidden layer and the tangent-sigmoid function in the hidden layer and the output layer showed the 1east-squares error and the highest correlation coefficient.

The results of 20 experiments were excluded from the experiments at the beginning of the modeling to be used for simulation at this stage. 
It is noteworthy that the network is not trained with this data, and if it can predict the correct results, it can be said that the network is reliable and usable.

The $\mathrm{pH}$ values, the initial concentration of 2-naphthol orange dye, mixing speed, mixing time, and absorption dose of 20 experiments were entered as input to the neural network model for the simulation; the prediction and test results, which represents the elimination percentage of 2-naphthol orange dye, is illustrated in Fig. 5.

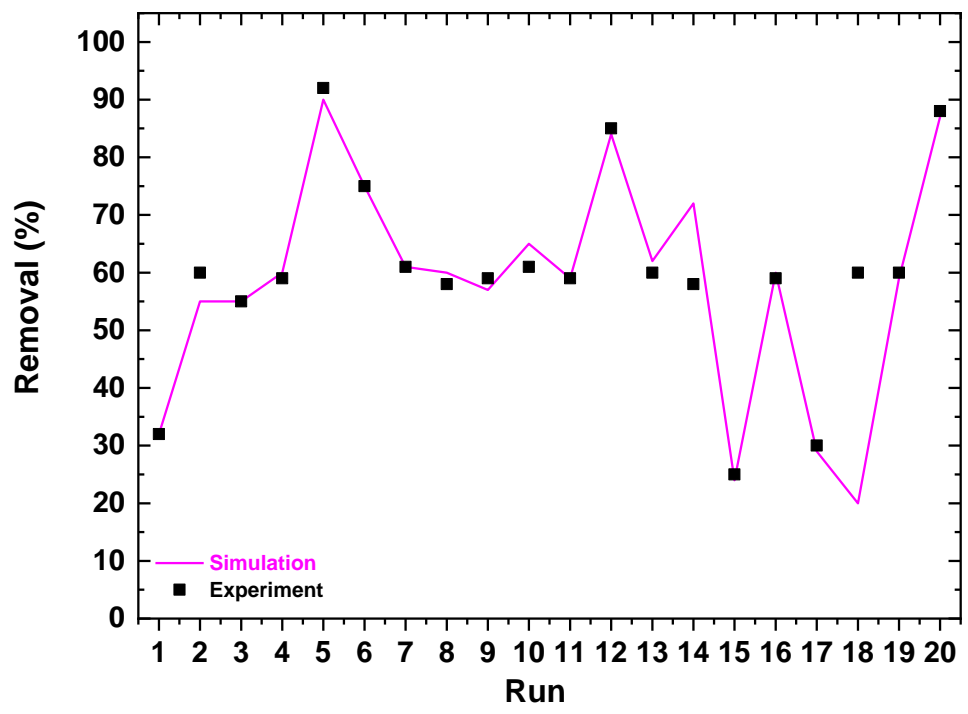

Figure 5. Comparison of neural network simulation results designed to predict the amount of 2-Naphthol Orange dye removal and laboratory results.

\subsection{Discussion.}

By increasing the absorption contact time with the considered solution, the adsorption rate increased, and it remained stable after reaching the equilibrium time, as shown in Fig. 2. Accordingly, the equilibrium time of absorption of 2-naphthol orange dye at the studied concentration range was obtained as $120 \mathrm{~min}$. To model the adsorption kinetics, quasi-first and quasi-quadratic models were used; the results showed the high agreement of color adsorption kinetics of 2-naphthol orange dye with the pseudo-second-order model. In 2020, Tanhaei et al. studied the absorption of methyl orange (MO) using the multi-walled carbon nanotubes (MWCNTs); they showed that the MO adsorption capacity increased by increasing the initial color concentration [35]. In 2011, Jiang G. et al. (2011) investigated methylene blue using multi-walled carbon nanotubes; in their study, the adsorption reaction's velocity was characterized by a false quadratic model; this was in line with the present study [10].

Langmuir and Freundlich are the most common models used to describe the adsorption process in this study. Using their linear form and regression, the model coefficients were obtained as presented in Table 2. Based on this, the maximum absorption rate was equal to $92.64 \mathrm{mg} / \mathrm{g}$ in optimal conditions. Plots of Langmuir and Freundlich isotherms in the initial concentration of $250 \mathrm{mg} / \mathrm{L}$ are illustrated in Fig. 3a and 3b. In all initial concentrations, the coefficient of $\mathrm{R}^{2}$ in Freundlich and Langmuir isotherms had a good agreement with the results; however, that of Freundlich even had a higher agreement. Madrakian et al., in 2011, studied cationic color elimination from aqueous solution using multi-walled carbon nanotubes, analyzing their research data by the Langmuir adsorption model [6].

After conducting the factorial design, optimum conditions were obtained at the initial concentration of $250 \mathrm{mg} / \mathrm{L}$, absorption dose of $0.07 \mathrm{~g} / \mathrm{L}$, $\mathrm{pH}$ of 3, mixing velocity of $200 \mathrm{rpm}$, mixing time of 120 min with maximum elimination $99 \%$. In 2011, Machado et al. (2011) 
investigated the effects of initial $\mathrm{pH}$ on the elimination rate of reactive red M-2 BE (RRM) in aqueous solutions; they showed that by using multi-walled carbon nanotubes and increasing the $\mathrm{pH}$ value from 2 to 10 , the color removal efficiency was decreased [2]. Shanmuga et al., in their study, prepared the color solution with $\mathrm{pH} 5,7,9$, and 11. The optimum condition of adsorption at $\mathrm{pH}=5$ and the removal efficiency of multi-walled carbon nanotubes in removing the studied acid color in the present research was $92.5 \%$ in acidic conditions [36].

In this study, neural network models were developed to predict the amount of orange dye adsorption. One of the most important parts of designing a network is determining the type of transfer function and the number of neurons in the hidden layers. Transfer functions are of great importance due to their role in converting the internal data into the output. In most research works, these functions are selected without an initial examination. In this study, in the first step, the best transfer function was selected by developing four neural network models using a combination of linear and sigmoid transfer functions. According to Fig. 4, the first model had the lowest correlation coefficient (0.893) and the maximum error (99.3) by having a linear transfer function in the hidden and output layers. The fourth model had the least-squares error (48.48) and the maximum correlation coefficient (0.986) by applying the tangent-sigmoid transfer function in the hidden and output layers.

In the fourth model, the best mode has occurred in epoch 14th or in the 14th time all the data entered into the model for modifying the weights. The result seems reasonable because the error in the experimental and appraisal sets has similar characteristics; thus, there is no overfitting.

The next step is to perform a series of analyses on the network response; in this regard, all the experimental and appraisal training data is applied to the network to obtain the linear regression between the network output and target vector, which are the experimental results. The correlation coefficient between the model's predicted outputs and the experimental outputs given to the model is 0.986 . This result is also reasonable as R-value is close to 1 , and there is a good correlation between the network output and the target vector.

Finding the most appropriate transfer function in the hidden and output layer, the next step aims to determine the number of optimal neurons in the neurons in the hidden layer of the network if, according to the result obtained in the previous phase, the transfer function in the hidden and output layer is the tangent-sigmoid function.

According to Table 3, the least-squares error rate and the highest correlation coefficients have occurred in the total number of 13 neurons. From 1 to 13 neurons, generally, the mean-square error decreases, followed by the increase. The correlation coefficient also slowly increased from 1 to 13 neurons and decreased by increasing the neurons' number. Further, by increasing the number of neurons to more than 20 , the mean-square error rate increases, and the correlation coefficient decreases with a dramatic slope. This means that increasing the number of neurons does not always improve the network's performance, but the number of neurons must be proportional to the number of input data. In this work, the number of input data is 80 , and the number of appropriate neurons is between 10 and 13 . Therefore, the number of neurons must be between 1.2 and 1.6 of the input data.

At this step, the optimal network is constructed with the tangent-sigmoid transfer functions and 13 neurons in the hidden layer. According to the results, this network has high performance since the mean-square error is small, about 8.02. Also, the experimental set error and the appraisal set error have similar behaviors and characteristics. Until the 5 repeats with the best performance in the appraisal set, no overfitting occurs; further, the network does not 
suffer early training. The output of the experimental, appraisal and testing sets are adjusted well with the target vectors, with R-value close to 1 . Given that the network reaction is appropriate, it is possible to simulate the network in terms of previous or new data.

In 2014, the slight/superficial adsorption process of a metal-complex dyestuff (black acid 172) was simulated using bamboo wood ash (biochar Bamboo) by artificial neural networks with different structures [37]. In 2016, artificial neural networks were used to remove crystal violet dyestuff using the rod-shaped nanoparticles of zinc oxide $(\mathrm{ZnO})$ loaded on active carbon. The effective variables, including ultrasound time for slight adsorption, initial concentration of dyestuff, and absorbent dose, were optimized by the experimental design method. The prediction of the elimination percentage with artificial neural networks was made based on experimental data [38].

The simulation was carried out with a trained network, and the data with available experimental results entered into the network; however, this data was not given to the network at the time of training. In this research, 20 of the experiments were considered for the simulation, being entered into the trained network. According to Fig. 5, the model's predictions for these data and the experiments' results have quite a similar trend with a good agreement.

\section{Conclusions}

The modified adsorbent of wheat bran used in this study can remove 2-naphthol orange dye from aquatic environments; thus, it can be used as an efficient and economical option instead of conventional adsorbents color-contaminated wastewater treatment. The equilibrium time of the 2-naphthol orange adsorption by adsorbent of wheat bran is achieved $120 \mathrm{~min}$ at a concentration of $250 \mathrm{mg} / \mathrm{L}$; its adsorption kinetics follows the pseudo-order -2 model. In this study, the adsorption's optimum $\mathrm{pH}$ is 3 , and the optimal mixing velocity is $200 \mathrm{rpm}$. The maximum adsorption capacity is obtained by the modified wheat bran is $92.64 \mathrm{mg} / \mathrm{g}$, which corresponds to the Langmuir and Freundlich models. Further, a Feedforward Backpropagation Neural network (FFBPANN) is designed to predict the amount of the 2-naphthol orange absorption from aqueous solutions using modified wheat bran as an adsorbent. A three-layer network is optimal, in which the number of neurons in the hidden layer is 13 . Using the Levenberg-Marquardt training function and the tangent -sigmoid transfer function at the hidden and output layers and the number of neurons between 1.2 to 1.6 of the input data, provide appropriate results for the prediction of the adsorption process. The correlation coefficient between the model's predicted outputs and the experimental outputs are given to the model is 0.986. The model results are very similar to those of the experimental. Therefore, the neural network can be a suitable technique to model, estimate, and predict the adsorption process.

\section{Funding}

This research received no external funding.

\section{Acknowledgments}

This research has no acknowledgment.

\section{Conflicts of Interest}

The authors declare no conflict of interest. 


\section{References}

1. Jiang, D.; Chen, M.; Wang, H.; Zeng, G.; Huang, D.; Cheng, M.; Liu, Y.; Xue, W.; Wang, Z. The application of different typological and structural MOFs-based materials for the dyes adsorption. Coordination Chemistry Reviews 2019, 380, 471-483, https://doi.org/10.1016/j.ccr.2018.11.002.

2. Zheng, Y.; Yang, Y.; Zhang, Y.; Zou, W.; Luo, Y.; Dong, L.; Gao, B. Facile one-step synthesis of graphitic carbon nitride-modified biochar for the removal of reactive red 120 through adsorption and photocatalytic degradation. Biochar 2019, 1, 89-96, https://doi.org/10.1007/s42773-019-00007-4.

3. De Benedetto, C.; Macario, A.; Siciliano, C.; B. Nagy, J.; De Luca, P. Adsorption of Reactive Blue 116 Dye and Reactive Yellow 81 Dye from Aqueous Solutions by Multi-Walled Carbon Nanotubes. Materials 2020, 13, https://doi.org/10.3390/ma13122757.

4. Ahmadi, S.; Mohammadi, L.; Rahdar, A.; Rahdar, S.; Dehghani, R.; Adaobi Igwegbe, C.; Kyzas, G.Z. Acid Dye Removal from Aqueous Solution by Using Neodymium(III) Oxide Nanoadsorbents. Nanomaterials 2020, 10, https://doi.org/10.3390/nano10030556.

5. Seyed Arabi, S.M.; Lalehloo, R.S.; Olyai, M.R.T.B.; Ali, G.A.M.; Sadegh, H. Removal of congo red azo dye from aqueous solution by $\mathrm{ZnO}$ nanoparticles loaded on multiwall carbon nanotubes. Physica E: Lowdimensional Systems and Nanostructures 2019, 106, 150-155, https://doi.org/10.1016/j.physe.2018.10.030.

6. Madrakian, T.; Afkhami, A.; Ahmadi, M.; Bagheri, H. Removal of some cationic dyes from aqueous solutions using magnetic-modified multi-walled carbon nanotubes. Journal of Hazardous Materials 2011, 196, 109-114, https://doi.org/10.1016/j.jhazmat.2011.08.078.

7. Eslami, H.; Shariatifar, A.; Rafiee, E.; Shiranian, M.; Salehi, F.; Hosseini, S.S.; Eslami, G.; Ghanbari, R.; Ebrahimi, A.A. Decolorization and biodegradation of reactive Red 198 Azo dye by a new Enterococcus faecalis-Klebsiella variicola bacterial consortium isolated from textile wastewater sludge. World Journal of Microbiology and Biotechnology 2019, 35, https://doi.org/10.1007/s11274-019-2608-y.

8. Kamarehie, B.; Jafari, A.; Ghaderpoori, M.; Amin Karami, M.; Mousavi, K.; Ghaderpoury, A. Catalytic ozonation process using PAC/ $\gamma$-Fe2O3 to Alizarin Red S degradation from aqueous solutions: a batch study. $\begin{array}{lllll}\text { Chemical Engineering } & \text { Communications }\end{array}$ https://doi.org/10.1080/00986445.2018.1537266.

9. Abd-Elhamid, A.I.; Kamoun, E.A.; El-Shanshory, A.A.; Soliman, H.M.A.; Aly, H.F. Evaluation of graphene oxide-activated carbon as effective composite adsorbent toward the removal of cationic dyes: Composite preparation, characterization and adsorption parameters. Journal of Molecular Liquids 2019, 279, 530-539, https://doi.org/10.1016/j.molliq.2019.01.162.

10. Tahir, M.B.; Farman, S.; Rafique, M.; Shakil, M.; Khan, M.I.; Ijaz, M.; Mubeen, I.; Ashraf, M.; Nadeem Riaz, K. Photocatalytic performance of hybrid WO3/TiO2 nanomaterials for the degradation of methylene blue under visible light irradiation. International Journal of Environmental Analytical Chemistry 2019, 1-13, https://doi.org/10.1080/03067319.2019.1685093.

11. Abdelrahman, E.A.; Hegazey, R.M.; Kotp, Y.H.; Alharbi, A. Facile synthesis of Fe2O3 nanoparticles from Egyptian insecticide cans for efficient photocatalytic degradation of methylene blue and crystal violet dyes. Spectrochimica Acta Part A: Molecular and Biomolecular Spectroscopy 2019, 222, https://doi.org/10.1016/j.saa.2019.117195.

12. Radi, M.A.; Nasirizadeh, N.; Mirjalili, M.; Rohani Moghadam, M. Ultrasound-assisted electrochemical decolorization of anthraquinone dye C.I Reactive Blue 49, its optimization and synergic effect: a comparative study. International Journal of Environmental Science and Technology 2019, 16, 2455-2464, https://doi.org/10.1007/s13762-017-1638-y.

13. Ullah, I.; Nadeem, R.; Iqbal, M.; Manzoor, Q. Biosorption of chromium onto native and immobilized sugarcane bagasse waste biomass. Ecological Engineering 2013, 60, 99-107, https://doi.org/10.1016/j.ecoleng.2013.07.028.

14. Alalwan, H.A.; Kadhom, M.A.; Alminshid, A.H. Removal of heavy metals from wastewater using agricultural by-products. Journal of Water Supply: Research and Technology-Aqua 2020, 69, 99-112, https://doi.org/10.2166/aqua.2020.133.

15. Wu, H.; Wu, Q.; Zhang, J.; Gu, Q.; Wei, L.; Guo, W.; He, M. Chromium ion removal from raw water by magnetic iron composites and Shewanella oneidensis MR-1. Scientific Reports 2019, 9, https://doi.org/10.1038/s41598-018-37470-1.

16. Özsin, G.; Kılıç, M.; Apaydın-Varol, E.; Pütün, A.E. Chemically activated carbon production from agricultural waste of chickpea and its application for heavy metal adsorption: equilibrium, kinetic, and thermodynamic studies. Applied Water Science 2019, 9, https://doi.org/10.1007/s13201-019-0942-8.

17. Shen, Z.; Hou, D.; Jin, F.; Shi, J.; Fan, X.; Tsang, D.C.W.; Alessi, D.S. Effect of production temperature on lead removal mechanisms by rice straw biochars. Science of The Total Environment 2019, 655, 751-758, https://doi.org/10.1016/j.scitotenv.2018.11.282.

18. Sun, C.; Chen, T.; Huang, Q.; Wang, J.; Lu, S.; Yan, J. Enhanced adsorption for Pb(II) and Cd(II) of magnetic rice husk biochar by KMnO4 modification. Environmental Science and Pollution Research 2019, 26, 89028913, https://doi.org/10.1007/s11356-019-04321-z. 
19. Ma, J.; Li, T.; Liu, Y.; Cai, T.; Wei, Y.; Dong, W.; Chen, H. Rice husk derived double network hydrogel as efficient adsorbent for $\mathrm{Pb}(\mathrm{II}), \mathrm{Cu}(\mathrm{II})$ and $\mathrm{Cd}(\mathrm{II})$ removal in individual and multicomponent systems. Bioresource Technology 2019, 290, https://doi.org/10.1016/j.biortech.2019.121793.

20. Popoola, L.T. Nano-magnetic walnut shell-rice husk for Cd(II) sorption: design and optimization using artificial intelligence and design expert. Heliyon 2019, 5, https://doi.org/10.1016/j.heliyon.2019.e02381.

21. Ahmad, M.F.; Haydar, S.; Bhatti, A.A.; Bari, A.J. Application of artificial neural network for the prediction of biosorption capacity of immobilized Bacillus subtilis for the removal of cadmium ions from aqueous solution. Biochemical Engineering Journal 2014, 84, 83-90, https://doi.org/10.1016/j.bej.2014.01.004.

22. Yetilmezsoy, K.; Demirel, S. Artificial neural network (ANN) approach for modeling of Pb(II) adsorption from aqueous solution by Antep pistachio (Pistacia Vera L.) shells. J Hazard Mater 2008, 153, 1288-1300, https://doi.org/10.1016/j.jhazmat.2007.09.092.

23. Bagheri, M.; Mirbagheri, S.A.; Bagheri, Z.; Kamarkhani, A.M. Modeling and optimization of activated sludge bulking for a real wastewater treatment plant using hybrid artificial neural networks-genetic algorithm approach. Process Safety and Environmental Protection 2015, 95, 12-25, https://doi.org/10.1016/j.psep.2015.02.008.

24. Ding, Y.R.; Cai, Y.J.; Sun, P.D.; Chen, B. The Use of Combined Neural Networks and Genetic Algorithms for Prediction of River Water Quality. Journal of Applied Research and Technology 2014, 12, 493-499, https://doi.org/10.1016/S1665-6423(14)71629-3.

25. Joo, S.; Yoon, J.; Kim, J.; Lee, M.; Yoon, Y. NOx emissions characteristics of the partially premixed combustion of $\mathrm{H} 2 / \mathrm{CO} / \mathrm{CH} 4$ syngas using artificial neural networks. Applied Thermal Engineering 2015, 80, 436-444, https://doi.org/10.1016/j.applthermaleng.2015.01.057.

26. Bunsan, S.; Chen, W.-Y.; Chen, H.-W.; Chuang, Y.H.; Grisdanurak, N. Modeling the dioxin emission of a municipal solid waste incinerator using neural networks. Chemosphere 2013, 92, 258-264, https://doi.org/10.1016/j.chemosphere.2013.01.083.

27. Yang, Y.; Wang, G.; Wang, B.; Li, Z.; Jia, X.; Zhou, Q.; Zhao, Y. Biosorption of Acid Black 172 and Congo Red from aqueous solution by nonviable Penicillium YW 01: Kinetic study, equilibrium isotherm and artificial neural network modeling. Bioresource Technology 2011, 102, 828-834, https://doi.org/10.1016/j.biortech.2010.08.125.

28. Xu, S.; Ng, J.; Zhang, X.; Bai, H.; Sun, D.D. Adsorption and photocatalytic degradation of Acid Orange 7 over hydrothermally synthesized mesoporous TiO2 nanotube. Colloids and Surfaces A: Physicochemical and Engineering Aspects 2011, 379, 169-175, https://doi.org/10.1016/j.colsurfa.2010.11.032.

29. Borror, C.M.; Montgomery, D.C. Mixed resolution designs as alternatives to Taguchi inner/outer array designs for robust design problems. Quality and Reliability Engineering International 2000, 16, 117-127, https://doi.org/10.1002/(SICI)1099-1638(200003/04)16:2<117::AID-QRE309>3.0.CO;2-0.

30. Shanmugaprakash, M.; Sivakumar, V. Development of experimental design approach and ANN-based models for determination of $\mathrm{Cr}(\mathrm{VI})$ ions uptake rate from aqueous solution onto the solid biodiesel waste residue. Bioresource Technology 2013, 148, 550-559, https://doi.org/10.1016/j.biortech.2013.08.149.

31. Rafiq, Y.; Bugmann, G.; Easterbrook, D.J. Neural network design for engineering application. Computers \& Structures 2001, 79, 1541-1552, https://doi.org/10.1016/S0045-7949(01)00039-6.

32. Igwegbe, C.A.; Mohmmadi, L.; Ahmadi, S.; Rahdar, A.; Khadkhodaiy, D.; Dehghani, R.; Rahdar, S. Modeling of adsorption of Methylene Blue dye on Ho-CaWO4 nanoparticles using Response Surface Methodology (RSM) and Artificial Neural Network (ANN) techniques. MethodsX 2019, 6, 1779-1797, https://doi.org/10.1016/j.mex.2019.07.016.

33. Bilski, J.; Kowalczyk, B.; Marchlewska, A.; Zurada, J.M. Local Levenberg-Marquardt Algorithm for Learning Feedforwad Neural Networks. Journal of Artificial Intelligence and Soft Computing Research 2020, 10, 299-316, https://doi.org/10.2478/jaiscr-2020-0020.

34. Altowayti, W.A.H.; Haris, S.A.; Almoalemi, H.; Shahir, S.; Zakaria, Z.; Ibrahim, S. The removal of arsenic species from aqueous solution by indigenous microbes: Batch bioadsorption and artificial neural network model. Environmental Technology \& Innovation 2020, 19, https://doi.org/10.1016/j.eti.2020.100830.

35. Tanhaei, B.; Ayati, A.; Iakovleva, E.; Sillanpää, M. Efficient carbon interlayed magnetic chitosan adsorbent for anionic dye removal: Synthesis, characterization and adsorption study. International Journal of Biological Macromolecules 2020, 164, 3621-3631, https://doi.org/10.1016/j.ijbiomac.2020.08.207.

36. Kittappa, S.; Jais, F.M.; Ramalingam, M.; Mohd, N.S.; Ibrahim, S. Functionalized magnetic mesoporous palm shell activated carbon for enhanced removal of azo dyes. Journal of Environmental Chemical Engineering 2020, 8, https://doi.org/10.1016/j.jece.2020.104081.

37. Yang, Y.; Lin, X.; Wei, B.; Zhao, Y.; Wang, J. Evaluation of adsorption potential of bamboo biochar for metal-complex dye: equilibrium, kinetics and artificial neural network modeling. International Journal of Environmental Science and Technology 2014, 11, 1093-1100, https://doi.org/10.1007/s13762-013-0306-0.

38. Dil, E.A.; Ghaedi, M.; Ghaedi, A.; Asfaram, A.; Jamshidi, M.; Purkait, M.K. Application of artificial neural network and response surface methodology for the removal of crystal violet by zinc oxide nanorods loaded on activate carbon: kinetics and equilibrium study. Journal of the Taiwan Institute of Chemical Engineers 2016, 59, 210-220, https://doi.org/10.1016/j.jtice.2015.07.023. 